\title{
Investigating municipal solid waste management system performance during the Arba'een event in the city of Kerbala, Iraq
}

\author{
Muhammad Abdulredha, et al. [full author details at the end of the article]
}

Received: 3 April 2018 / Accepted: 20 September 2018 / Published online: 21 September 2018

(C) The Author(s) 2018

\begin{abstract}
Every year, many religious events attended by 300 million pilgrims take place in many holy cities and sites around the world. However, research on municipal solid waste is limited despite the reputation of religious events to generate substantial amounts of waste. This research aims to address this gap and contribute to new knowledge on municipal solid waste management at religious events by investigating and evaluating the municipal solid waste management system applied at the Arba'een event in Kerbala, one of the largest religious events in Iraq. Field observations and in-depth interviews with nine senior managers from Kerbala's municipalities were conducted during the event in 2016, to develop an overall picture of the municipal solid waste management system applied during the event. The data were analysed using thematic analysis and fed to the 'Wasteaware' benchmark indicators framework to evaluate the performance of the event system. The results indicated that the system suffers from operational and governance weaknesses. Despite a focus on municipal solid waste collection and transportation, the collection coverage is only $\sim 70 \%$. There is no controlled landfill site in Kerbala. It is estimated that currently $\sim 5 \%$ of the event municipal solid waste is recycled by informal recyclers: there is no formal recycling scheme. Kerbala does not perform well regarding governance. The inclusivity of providers and users of the municipal solid waste management services is minimal during the event, as the majority of stakeholders are not included in decision-making processes. Municipal solid waste management services are delivered free of charge, thus significantly influencing the financial sustainability of the system. This study recommends that MSW recycling should be encouraged through integrating the informal sector, improving public awareness and introducing a formal recycling scheme to make the event municipal solid waste management system effective and financially sustainable.
\end{abstract}

Keywords Integrated municipal solid waste management $\cdot$ Kerbala $\cdot$ Municipal solid waste management indicators $\cdot$ Municipal solid waste $\cdot$ Religious events $\cdot$ Performance assessment

Electronic supplementary material The online version of this article (https://doi.org/10.1007/s1066 8-018-0256-2) contains supplementary material, which is available to authorized users. 


\section{Introduction}

Tourism is one of the leading industries around the world, growing by $7 \%$ in 2017 . As a third export sector, it is one of the key drivers for job creation and economic development (UNWTO 2018). One form of the tourism is religious events (El Hanandeh 2013), where individuals of a particular faith travel to participate in events of spiritual significance. Religious events have become customary worldwide, attracting millions of pilgrims every year. El Hanandeh (2013) reported approximately 300 million individuals participating in worldwide religious events on an annual basis. Thus, events are responsible for generating huge quantities of municipal solid waste (MSW) and are attributed as increasing the probability of serious negative impacts on the environment (Abdulredha et al. 2018a). There is a level of awareness of these issues as evidenced by El Hanandeh (2013), who proposed several alternatives to minimise the greenhouse gases emissions from municipal solid waste management (MSWM) operations during Hajj events. This state of affairs has intensified the pressure on MSWM establishments to develop policies and actions to tackle these problems (Lundmark and Stjernström 2009).

MSWM is a set of activities and actions that are required to manage MSW from its origin to its final destination (Wilson et al. 2012). This includes storage at source, collection, transportation, treatment and final disposal of the MSW, together with proper monitoring. It also encompasses legal and regulatory frameworks, development plans/strategies and stakeholder involvement schemes (Wilson et al. 2015). MSWM is a key function service, a city governance provision on which the public health and the attractiveness of a city depend (Wilson et al. 2013a). It is also a major environmental challenge (Arbulu et al. 2015,2016 ) and one, which is exacerbated in some tourist destinations due to limited land, the increasing cost of management and the deterioration of the image of the destination (Gómez et al. 2008). Because of this, it is vital to analyse this service especially relative to tourist destinations (Mateu-Sbert et al. 2013). Using properly developed indicators allows a city to review its own performance, in terms of service delivery, thus helping decisionmakers to prioritise their actions for improvement (Wilson et al. 2015).

Researchers (Caio and Fernando 2013; Hotta 2014; Wilts 2012; Zaman 2014) have developed indicators to measure the performance of particular aspects of MSWM systems. These have included MSW collection, collection of recyclables (Caio and Fernando 2013), resource management (reduce, reuse, recycle) (Hotta 2014), MSW prevention (Wilts 2012) and zero waste management (Zaman 2014). Other indicators have been developed to examine other aspects including measuring the compliance with European Union requirements (Cifrian et al. 2012), comparing MSWM technologies (Menikpura et al. 2012) and evaluating MSWM programmes in US cities (Greene and Tonjes 2014). Among these, 'Wasteaware' benchmark indicators for integrated and sustainable waste management systems (Wilson et al. 2015) comprehensively cover all aspects of an MSWM service. Wasteaware benchmark indicator framework contains 12 quantitative and qualitative indicators used to evaluate any MSWM system according to its physical components (collection, disposal and recycling) and governance features (stakeholders' inclusivity, financial suitability and sound institutions) (Wilson et al. 2015). This framework has been developed over 5 years (Wilson et al. 2015) and has been tested in more than 50 cities around the world (Wilson et al. 2013a, b, 2015; Scheinberg et al. 2010; Wilson 2007). Thus, it can be considered as a well-developed framework, broadly covering all the features of the MSWM system, applied across a range of income levels and widely tested across a number of countries (Wilson et al. 2015). 
Research on MSWM systems has predominantly focused on high-income countries. There has been limited focus on developing countries (Wilson et al. 2013a) in addition to a paucity of academic literature on MSWM systems at large events (Martinho et al. 2018). That said, religious and cultural events have occupied a significant role in tourism-related research (Getz and Page 2016). Panfiluk (2015) studied the impact of events on the level of employment and income in Poland, while Giovanardi et al. (2014) investigated the interactions between the residents and the visitors of the 'Pink Night' event in Italy. Matheson et al. (2014) studied the impact of spiritual attitudes on visitor attendance to the Beltane Fire event in Edinburgh, while Buzinde et al. (2014) explored the experiences, activities and motivations of pilgrims on the Kumbh Mela pilgrimage, India.

However, Getz and Page (2016) reported that research has largely neglected the environmental aspects of tourism events. Research specific to environmental aspects of large events has covered a wide range of topics including waste generation (Abdulredha et al. 2018a), waste recycling intention and behaviour (Alsebaei 2014), waste prevention measures (Martinho et al. 2018), environmental impact (Collins and Cooper 2016), evaluating the environmental sustainability (Collins et al. 2012), litter management (Cierjacks et al. 2012) and carbon footprint (El Hanandeh 2013). Zeng et al. (2014) investigated greenhouse gases emissions from MSW generated at the Shanghai Expo, 2010 while Rafiee et al. (2018) studied the impacts of several religious and non-religious events on recycling a fraction of MSW in Tehran, Iran.

However, within event research, few studies (Alsebaei 2014; Arbulu et al. 2016) have considered the evolution of particular aspects of MSWM systems in tourist destinations, particularly during large religious events. This study therefore aims to address some of the shortage in research regarding MSWM during religious events by investigating and assessing the MSWM system currently applied in Kerbala during the Arba'een, one of the largest religious events in Iraq and in the world. The system adopted during the aforementioned event was evaluated using Wasteaware indicators. As there are no previous studies comprehensively investigating the MSWM during the Arba'een, the data for this study has been drawn from official documents, detailed interviews with senior managers in Kerbala municipalities and field observations during the Arba'een in 2016. The findings from this study can provide information for researchers and policymakers in the field of MSWM to establish plans that would help to improve the weaknesses of MSWM during large events and address the paucity of historical data on MSWM systems in developing countries. It also recommends potential future action to help Kerbala MSWM institutions to develop event MSWM systems.

\section{Methods}

\subsection{Study area and event}

Kerbala is situated in the middle of Iraq, approximately $100 \mathrm{~km}$ to the southwest of the Iraqi capital, Baghdad (see Fig. 1). Covering about 1.2\% of the total area of the country, it has an area of $5043 \mathrm{~km}^{2}$ (Abdulredha et al. 2018b). Constituting 3.2\% of the Iraqi population with a population density of 223 capita per $\mathrm{km}^{2}$, the city has a population of 1,151,152 according to the Central Statistical Organization, Iraq (CSOI 2015). Millions of pilgrims gather every year in the city during a number of religious events (Mujtaba Husein 2018). 


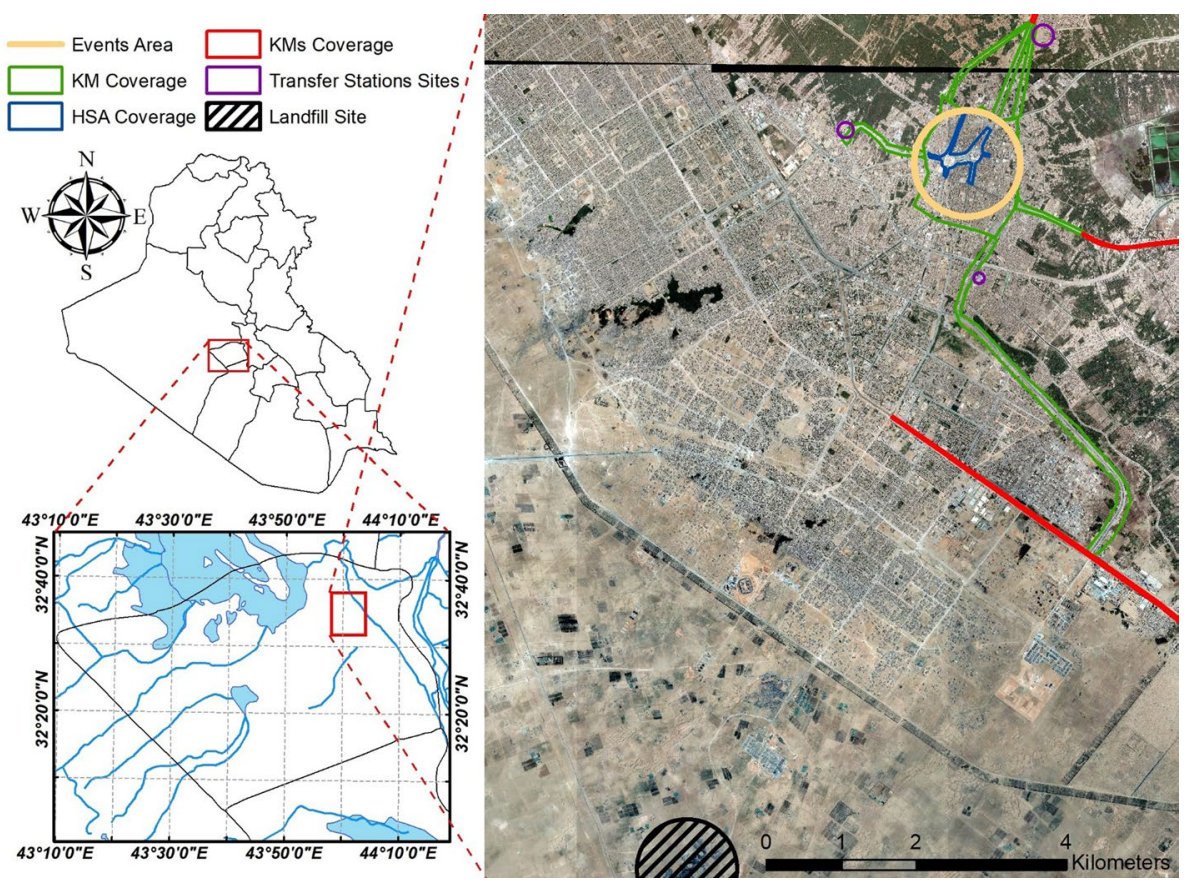

Fig. 1 Waste management institutions areas of jurisdiction in Kerbala during events

The Arba'een is one of the largest annual religious events which takes place in Kerbala, attracting 20 million pilgrims (Mujtaba Husein 2018), and lasting up to 15 days (Abdulredha et al. 2017d). In this event, pilgrims travel to Kerbala to visit the shrine of Imam Hussain (the grandson of the Prophet Muhammad) to commemorate his martyrdom with his companions and family, adopting various modes of transportation such as walking on foot (Mujtaba Husein 2018). Al-Modarresi (2014) reported that pilgrims who walk hundreds of miles from other Iraqi cities, or cross the border from other countries, do not need to carry anything except the clothes they wear as there are thousands of service camps (known as 'Mawakibs') lining the pilgrims paths, and in Kerbala city, that provide shelter, fresh food and all the needs of pilgrims, free of charge (Abdulredha et al. 2017c). The city also has 667 hotels (CSOI 2016), which tend to be fully occupied during this event. As a result, huge amounts of MSW are generated in the city during this event.

During religious events, MSWM activities such as collection, transportation and treatment are delivered by three government institutions; Kerbala Municipality (KM), Kerbala Municipalities (KMs) and the Holy Shrines Authority (HSA) (Abdulredha et al. 2018a). These institutions are responsible for all the MSWM across all the event areas (see Fig. 1). Their MSWM activities include collecting and dumping MSW into nearby landfill (Fig. 1) with no treatment or resources recovery such as recycling and composting (Abdulredha et al. 2017b, 2018a). Accurate data about the event MSW such as generation rates and composition do not exist, leading to weak planning and service delivery (Abdulredha et al. 2018a). This situation has led to an improper MSWM infrastructure and illegal MSW dumping (Abdulredha et al. 2017c). Al-Anbari et al. (2014) suggested that the MSWM situation in Kerbala has reached a state of crisis making it imperative that a critical evaluative 
study be applied to address the challenges facing Kerbala and enable management institutions to prioritise their actions to make improvements to the system.

\subsection{Municipal solid waste management system evaluation framework}

Wasteaware is a pre-developed evaluation framework that has a set of 12 indicators that comprehensively assess the performance of MSWM services from generation points to final destination (Wilson et al. 2015). Application helps to raise stakeholder awareness regarding MSWM service weaknesses and to identify system improvements by assigning a score to each criterion and indicator (Wilson et al. 2015). This framework was selected to evaluate MSWM during AL-Arba'een.

This framework evaluates the system over two dimensions: physical and technical components (collection, transportation, treatment and disposal) and governance features (financial suitability, institutional capacity, management policies and stockholders inclusivity). The physical and technical components are evaluated using seven quantitative and qualitative indicators, covering three key categories; collection, disposal and resource management (Wilson et al. 2015). The collection service is evaluated using three indicators; collection coverage, MSW captured by the management system and the quality of collection services. Likewise, the governance aspects of a system are assessed according to three main categories; inclusivity (users and providers), financial sustainability and the soundness of system institutions (national policies and local institutional coherence). For each of these, an assessment is made against 5-6 defined criteria, using professional judgment to assign a score $(0,5,10,15$ or 20$)$ against each criterion. The scores are then summed and normalised, if necessary, to provide a percentage normalised score.

The framework also requires a summary of background features and MSW-related data to facilitate interpretation of the indicators and provide an appropriate comparison between cities (Wilson et al. 2015). The background data consist of income category, total MSW generation and the total population while MSW-related data are yearly MSW generation per capita and the four common components of the MSW; organics, plastics, paper and metals (Wilson et al. 2015). The user manual offers detailed information on usefulness, definitions, interpretations and the scoring system of each indicator and criterion in this formwork. This is provided as Supplementary Material accompanying the Wilson et al. (2015) article.

\subsection{Data collection}

\subsubsection{Interview guide design and development}

The use of the Wasteaware framework requires mixed data (quantitative and qualitative) about the operations of the MSWM system such as the mode of MSW collection (Wilson et al. 2015). To gather comprehensive and mixed data, Bryman (2012) suggested that interviewing is useful technique. Accordingly, a semi-structured interview schedule was designed following the advice of Bryman (2012) such as selecting the interview guidance items and structure to collect comprehensive data about MSWM system applied in Kerbala during large religious events. The items in the schedule were formulated after carrying out a comprehensive literature review on MSWM and data collection and analysis techniques (Wilson et al. 2015; Arbulú et al. 2017; Alsebaei 2014; Getz and Page 2016; Peter 2016; Hashim et al. 2019). The schedule encompasses nine sections that cover wide range of 
MSWM aspects such as waste collection services; public education and involvement in MSWM services; and existing equipment and personal to deliver MSWM services (see supplementary materials). Then, the schedule was sent to a panel of MSWM and survey experts asking them to review the content and establish construct validity. Some changes were made in light of the experts' suggestions. In order to check potential areas of ambiguity and comprehensiveness, two key staffs (senior managers) from Kerbala MSWM institutions were asked to review the schedule and comment on its clarity.

\subsubsection{Conducting the investigation}

As KM, KMs and HSA are the only bodies responsible for provision of MSWM services during events, senior officers in these institutions who can best provide comprehensive and rich information on the MSWM system in Kerbala were targeted for this study. Bryman (2012) suggested that purposive sampling is a useful technique to identify participants relevant to the research question (how MSW is managed during the Arba'een event?). During the Arba'een in November 2016, the researcher approached 15 senior officers at the aforementioned bodies, to describe the objectives of the study and arrange an appointment for interview. Of these, 9 agreed to participate in this study. The interviews were anonymous and carried out both before and throughout the event. All interviews lasted between one to two hours, responses recorded through the use of notes as this study is not interested in the way the participants responded but what the participants had to say about the subject (Bryman 2012). At the end of each interview, the respondents reviewed the schedule to ensure that the data collected during the interview are correct and reflect the participant's views on the subjects involved.

The small number of participants is one of the weaknesses of the interviewing technique (Bryman 2012). Researchers such as Bryman (2015) and Peter (2016) have suggested a mixed method technique to collect comprehensive and reliable data regarding the research question; therefore, field observations were also carried out as a supporting data collection technique from the 1 October to the 24 November 2016. The goal of this observation was to reinforce the results of the interview, identify undocumented issues and define unexpected difficulties that faced management systems during the event. Unstructured observation was employed (Bryman 2012), as it enables the observer to note things that are unexpected. The observation focused on several aspects of the MSWM system including storage, collection, transportation and treatment of MSW during AL-Arba'een. The field observation data were compared with interview data and documentary resource. In all, the validity of the collected data was remarkably improved by this process.

\subsection{Data analysis}

As the official language in Iraq is Arabic, the interviews were conducted in Arabic. Prior to analysis, the interviews and field observation transcripts were translated into English by two qualified members of the authors. The amount of textual data (interview data) is substantial, requiring a high level of organisation to be analysed (Bryman 2015). QSR's NVivo version 11, a popular software program designed to analyse qualitative data, is used in this study (Bryman 2015). This software enables the researcher to label, separate, compile and organise textual components that seem to be important to the study for analyses (Bryman 2012). 
Thematic analysis is one of the prominent means of analysis in qualitative research and is the approach used in this study (Thomas and Harden 2008). It involves identifying, examining and recording themes within data sets (Bryman 2015). A theme is a pattern across the data that is significant to the description of a phenomenon related to the focus of the research (Thomas and Harden 2008). Ryan and Bernard (2003) recommend looking for repetitions, indigenous typologies, metaphors, transitions and linguistic connectors to identify themes.

In this study, this process was carried out over two overlapping stages: line-by-line coding of the interviewees' responses and the organisation of codes into related areas to construct themes. Initially, every sentence had at least one code applied to it, focusing on one aspect of MSWM operations (e.g. collection and treatment). When this was completed, all scripts were examined to check for consistency of coding and to consider whether additional levels of coding were required. This stage generated 307 codes that provided detailed information about the current activities of MSWM during the Arba'een including collection services, treatment practices, public involvement schemes. Then, similarities and differences between codes were examined to group codes into a hierarchical structure. Additional nodes were created to capture the meaning of the groups of initial codes. A tree structure comprising several layers was generated which allowed the organisation of 78 themes. Each theme provides detailed information regarding what was observed in the field and what participants had to say about specific aspects of the MSWM service. For instance, themes were created to provide information about the collection service including collection coverage, barriers facing the service, types of collection services, fleet sizes and collection service planning. The generated themes were then used to evaluate the MSWM system during AL-Arba'een, using Wasteaware benchmark indicators.

\section{Results and discussion}

\subsection{Background and affiliation of participants}

Nine senior officers, representing MSWM institutions in Kerbala, participated in the interviews conducted during the Arba'een in 2016. The participants' affiliations include $\mathrm{KM}, \mathrm{KMs}$ and HSA. Figure 2a shows that the majority of respondents (45\%) were from

\section{(a) Participant's Affiliations}

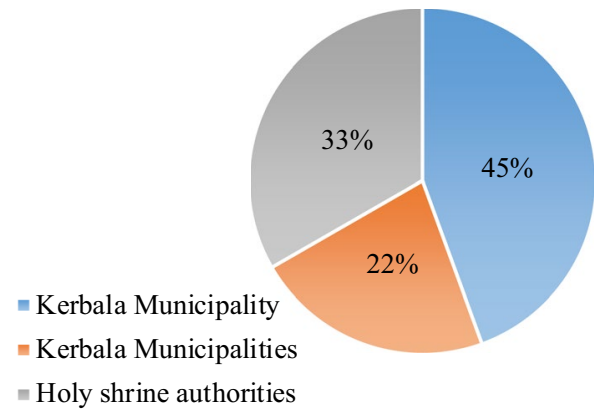

(b) Participants' Experiences
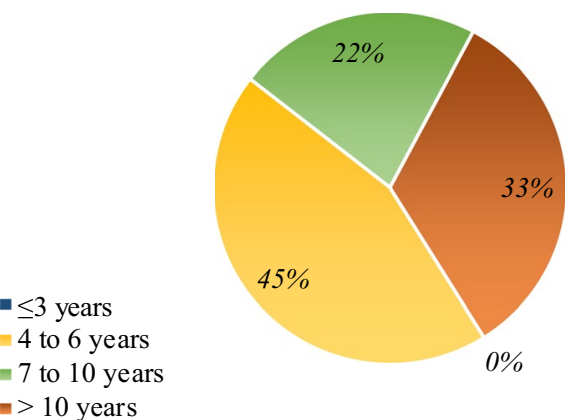

Fig. 2 Participant's background information 
$\mathrm{KM}$ as it is considered the authority with the largest management fleet. 33\% were from HSA, responsible for the collection of MSW in the central area of the city (Fig. 1). Two respondents were from KMs, in charge of MSW collection at the main entrances of the Arba' een event area (Fig. 1) (Abdulredha et al. 2017c). From Fig. 2b, it can be seen that the respondents were experienced, over half of whom with more than 7 years of involvement in MSWM. Almost all the participants had a Bachelor of Science degree, one with a Diploma qualification.

\subsection{City background information}

Reliable information about the background of a city (population and income level) and MSW-related data (quantity and composition) are of great importance in MSWM services planning, delivery and monitoring (Wilson et al. 2015). Respondents stated that MSW data is unavailable and has been estimated by MSWM institutions (KM, KMs, and HSA). According to CSOI (2015) and authorities' participants, the collected MSW from Kerbala was 560 kilo tonne (kt) in 2014. Each resident produces $2.1 \mathrm{~kg} \mathrm{day}^{-1}$, a figure which is significantly higher than the average MSW generation in other Iraqi cities (CSOI 2015) and other middle-income cities (Wilson et al. 2012). Interview respondents confirmed that large events significantly increase the amount of MSW generated in the city each year. According to the authorities' estimations, about $80 \mathrm{kt}$ of MSW is produced by large events on an annual basis. Of this, $48 \mathrm{kt}$ of MSW was generated during the Arba'een in 2015. This is higher than that produced by other pilgrimages such as World Youth Day (Catholic), 490 tonnes produced by 3.7 million pilgrims over 5 days (Salt \& Light 2013), by Kumbh Mela (Hindus), 300 tonnes produced by 8 million over 1 day (Gangwar and Joshi 2008), and from the Hajj event (Muslim), 17 kt produced by 3.69 million pilgrims over 5 days (Alsebaei 2014).

Table 1 provides a summary of the main components of the refuse collected during the Arba'een (Abdulredha et al. 2017c) and the refuse over the year (Al-masoudi and Al-haidary 2015). The Arba'een event MSW is comparable to the MSW normally generated in the city (Al-masoudi and Al-haidary 2015) and to the MSW produced in middle-income countries (Wilson et al. 2012). However, the Arba'een produces more organic waste (57.9\%) in comparison to generated during other religious events such as Kumbh Mela (51.8\%) (Gangwar and Joshi 2008) and Hajj (29.3\%) (Alsebaei 2014). This high fraction of organic MSW can be attributed to the availability and variety of free food and services during the event. Paper and plastics made up 29.5\% of the Arba'een refuse, which is lower than that generated during Hajj (52.6\%) (Alsebaei 2014) and higher than that produced during

Table 1 MSW composition by weight in Kerbala in 2015 (Al-masoudi and Al-haidary 2015) and in the Arba'een in 2016 (Abdulredha et al. 2017c)

\begin{tabular}{lll}
\hline MSW type & Kerbala city MSW (\%) & $\begin{array}{l}\text { The Arba'een } \\
\text { event MSW (\%) }\end{array}$ \\
\hline Organic waste & 56.6 & 57.9 \\
Plastic waste & 14.9 & 14.6 \\
Paper waste & 12.3 & 14.9 \\
Metal waste & 3.7 & 3.6 \\
Glass waste & 3.7 & 2.4 \\
Other waste & 8.8 & 6.5 \\
\hline
\end{tabular}


Kumbh Mela (10.89\%) (Gangwar and Joshi 2008). This can be attributed to the extensive use of packaging materials in both the Arba'een and Hajj events.

\subsection{Municipal solid waste management operations}

\subsubsection{Collection and transportation}

Table 2 summarises the resources employed by MSWM institutions to manage the MSW during the Arba'een in 2016. According to interviewees, institutions had more than 4000 personnel working in three shifts during the event to manage MSW. KM covered almost all of the event area (Fig. 1), with 2119 personnel (engineers, supervisors and labours), 419 pieces of equipment (collection trucks and heavy machinery) and almost 2000 storage bins (two- and four-wheeled). Figure 1 shows the jurisdiction areas for the three MSWM institutions.

According to respondents and to the author's observations, event areas are divided into several sections to which a supervisor is assigned to plan collection truck routes, making sure that all the MSW is collected and that the collection vehicle does not leave the area until is full. A group of workers were also assigned to each section, provided with distinctive clothing, gloves and safety shoes but they are lacking regular health checks. MSWM institutions collect most of the MSW generated during, or immediately after the event ends. Collections were made from more than $70 \%$ of the event area due to a high population density and the low mobility of collection vehicles. Field observations showed that most of the generated MSW was collected, specifically in main streets, up to 8 times per day. It is then transported in medium-sized, closed vehicles to Temporary Transfer Stations (TTSs) (Fig. 1) then onwards to a landfill site in larger opened vehicles (see Fig. 3d). The TTSs are sited in residential areas which have no fencing and suffer from a lack of controlled access and general site management. MSW located in narrow or inaccessible streets was left until the end of the event. Despite the high collection frequency and support from other cities, respondents and author's observations confirmed that there was a high incidence of MSW accumulation around the collection points, of littering and of illegal dumping due to the size of the event (Fig. 3a-c). This situation can lead to significant negative impact on the environment and public health.

Wilson et al. (2012) reported that 70-90\% is the poorest collection coverage observed in several middle-income cities. During AL-Arba'een, 70\% of the MSW was collected and transported to the landfill, this less than that achieved during Hajj (100\%) (Alsebaei 2014). In addition, a high incidence of littering, MSW accumulation around collection points,

Table 2 Summary of MSWM institutions' resources during the Arba' een event in 2016

\begin{tabular}{lllll}
\hline Item & \multicolumn{2}{l}{ Existing resources in each institution } & Total \\
\cline { 2 - 4 } & KM & KMs & HSA & \\
\hline Institution function & All event area except the & Main routes to the & Centre of the event & - \\
& centre (Fig. 1) & city (Fig. 1) & (Fig. 1) & 4134 \\
Human resources & 2119 & 936 & 1079 & 636 \\
Equipment resource & 419 & 193 & 24 & 600 \\
Storage bins & 1893 & 300 & 2793 \\
\hline
\end{tabular}




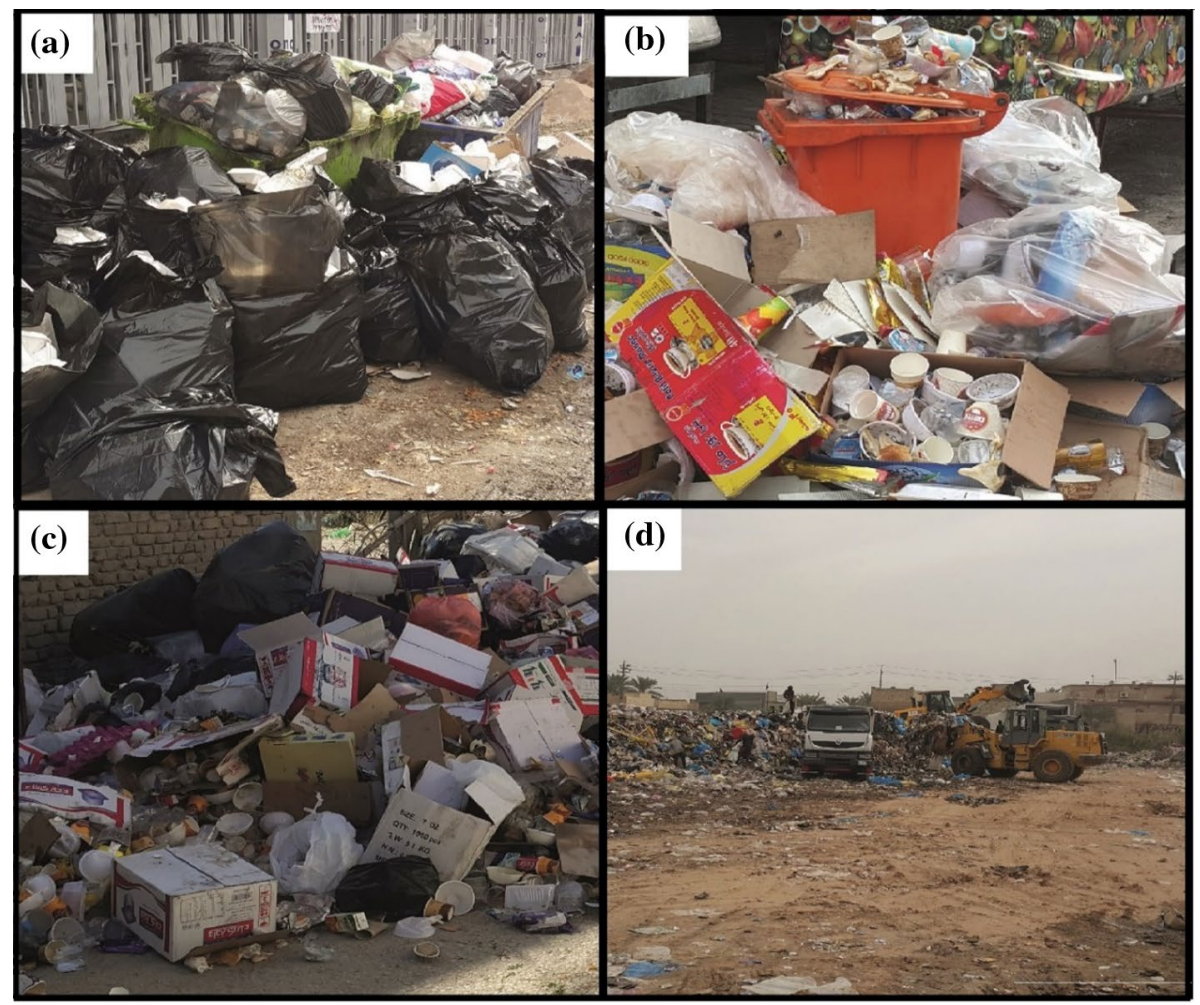

Fig. 3 Field observation of the collection system: a MSW accumulation around collection points, b litterbins overflowing, $\mathbf{c}$ illegal dumping and $\mathbf{d}$ TTS site

illegal dumping of MSW and improper siting and management of the TTSs was observed. This situation is similar to other large events such as Hajj (Alsebaei 2014), three open-air festivals in Germany (Cierjacks et al. 2012) and Kumbh Mela (Gangwar and Joshi 2008). Respondents attributed this to the low truck mobility due to overcrowding, inaccessible streets, blocked streets and poor planning.

\subsubsection{Municipal solid waste treatment and disposal}

The respondents and author's field observations confirmed that landfilling is used to manage the MSW generated in Kerbala and during large events. There is one landfill site, located about $10 \mathrm{~km}$ south of Kerbala, which has been approved by the Directorate of Kerbala Environment (Fig. 1). This site lacks fencing, access control, proper vehicular access, site security and MSW scales (see Fig. 4a). The site is semi-controlled, operated by KM with a compactor and two bulldozers. KM does not practise appropriate environmental control schemes nor do they carry out regular inspections of the site to ensure that it does not create negative impact on the environment. Thus, the site experiences occasional outbreaks of fire, uncontrolled emissions and leachate (Figs. 4b, c). The landfill is an old quarry where the MSW is normally dumped into the grooves of the soil, compacted and 


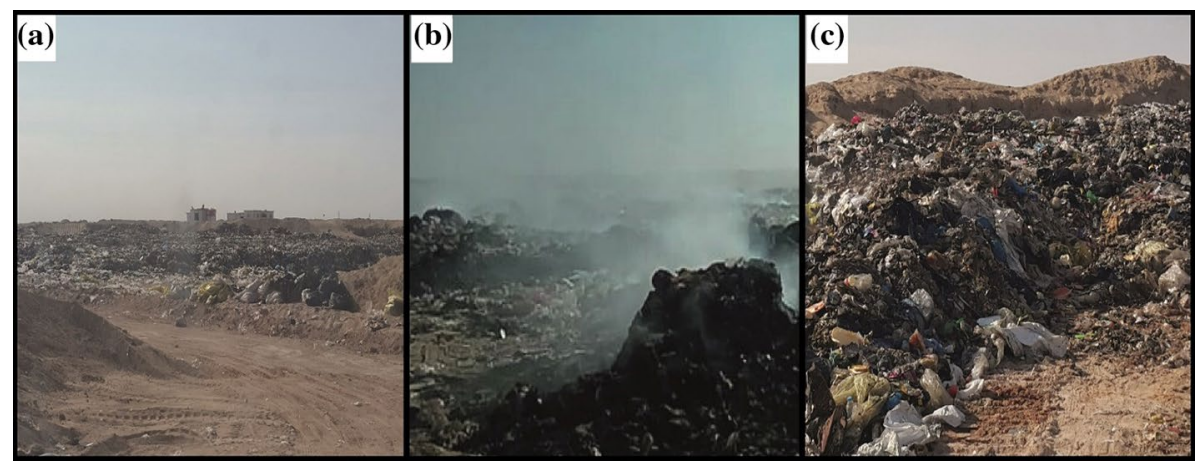

Fig. 4 Field observation of the landfill site: a entrance, $\mathbf{b}$ outbreak of fire, $\mathbf{c}$ control over leachate and emissions

occasionally covered with a thin layer of sand. The frontline staff normally wear boots, distinctive overalls and hats, but safe operating procedures and regular health checks are not in place.

The present MSW disposal practice in Kerbala is similar to several cities that host major events. For instance, the MSW generated during the Hajj event is dumped into a landfill site without control or treatment (Alsebaei 2014), while Kumbh Mela event MSW is disposed of in a site that is situated on a river bank with no segregation (Gangwar and Joshi 2008). The use of uncontrolled disposal facilities is considered a major failure compared to middle-income countries as Wilson et al. (2012) reported. Several middle-income cities have started developing state-of-the-art disposal facilities such as Kunming in China and Sousse in Tunisia.

\subsubsection{Recycling and resources management}

Scholars such as Zheng et al. (2016) and Alsebaei (2014) have stated that recycling offers a valuable alternative to increasingly expensive treatment options such as thermal treatment. However, both the interviewees' responses and author's field observations confirmed that formal recycling schemes do not exist in Kerbala, let alone during large events. Local institutions do not have a plan that endorses an MSWM hierarchy which should include reduction, reuse, recycling and recovery in spite of the large amounts of MSW produced in the city, particularly during religious events.

However, an active informal recycling sector has grown substantially over the last decade, scavengers sifting through and recovering recyclable material from collection points, TTSs and landfill sites (Fig. 5a, b). This sector is working on its own, as no organisation has made the effort to represent or include it within the formal MSWM system. MSWM institutions have no accurate estimates about the percentage of MSW that is recovered by this sector. However, interviewees estimated that $\sim 5 \%$ of the MSW is recovered; less than $25 \%$ of this is clean and source-separated. The majority of the recovered materials are plastic, metal and paper. There are some separations of organic materials at source to reduce food MSW contamination meaning it can then be used for animal feed. The MSW recovered by scavengers is normally separated at the landfill or TTS sites for reuse or recycling, giving a useful reduction in the MSW disposed of in the landfill. Informal sector activities not only reduce the environmental burden of MSW, but also enhance economic 


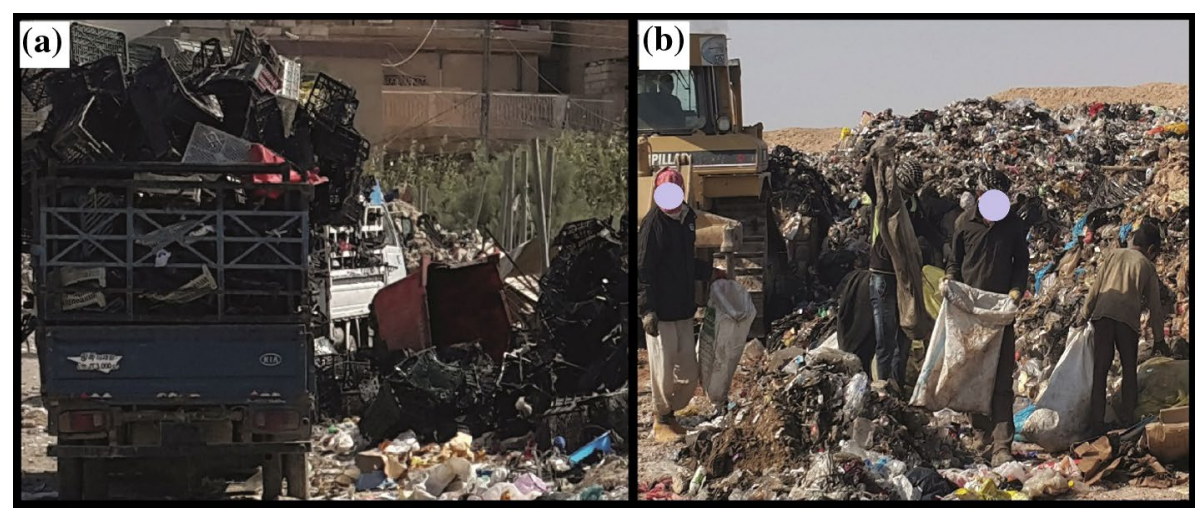

Fig. 5 Field observation of the informal recycling sector: a separated materials at a TTS and b informal recycling activities at the landfill site

opportunities (Masood et al. 2014). However, scavengers work in poor environmental conditions, having no appropriate clothing or equipment (e.g. safety shoes and gloves) nor an infrastructure for recycling purposes (Fig. 5b).

Although formal recycling during large events is adopted in many countries around the world such as Iran (Rafiee et al. 2018), China (Greene and Tonjes 2014) and Portugal (Martinho et al. 2018), this is not applied during the Arba'een event in Iraq and during the Hajj event in Saudi Arabia (Alsebaei 2014) and Kumbh Mela in India (Gangwar and Joshi 2008). Due to the absence of proper recycling infrastructures and planning, Kerbala still relies on informal recycling activities. Recycling rates of $\sim 5 \%$ by the informal sector are significantly less than that achieved in other events such as the 2008 Olympic Games in Beijing of 50\% (UNEP 2009) and the 1998 Del Mar Fairgrounds in California of 90\% (Barber et al. 2014). However, this figure is similar to those observed in cities such as Sousse and Lusaka in other developing countries that benefit from informal sector activities (Wilson et al. 2012).

\subsection{Governance aspects MSWM system}

The previous section revealed that Kerbala MSWM institutions were unable to provide adequate collection, safe treatment and disposal of the MSW generated during events. Governance aspects include the degree of stakeholders' involvement in MSWM services delivery and planning, MSWM system financial sustainability and MSWM institutional coherence all of which play an important role in the success of an MSWM system (Wilson et al. 2015).

\subsubsection{Stakeholders involvement}

The provision of a transparent space for stakeholders (users and non-government providers) to contribute to the planning and delivery of MSWM services significantly enhances the performance of any MSWM system (Wilson et al. 2012). Sheau-Ting et al. (2016) stated that the active participation of the MSWM system user is among the key elements which can improve MSWM services. In this regard, the authorities' representatives agreed that public involvement in the planning, application and evaluation of MSWM services is 
poor. There is no well-developed mechanism or legal obligation to ensure actual public involvement at appropriate stages of the MSWM services planning and implementation process. Besides this, the institutions have weak public education programmes regarding MSWM. There is no permanent public education scheme provided by schools or colleges. Printed posters are used, but these have had a negligible impact on public behaviour. A complaint system is active whereby complaints can be registered by phone. The current poor public involvement and awareness are similar to many developing countries such as Saudi Arabia (Alsebaei 2014) and Bangladesh (Ahmed and Ali 2006). This situation can lead to lost opportunities for the improvement of the MSWM system.

Provider involvement refers to the degree to which non-governmental bodies are involved in the planning and delivery of MSWM services (Wilson et al. 2015). Interviewees recognised that both the public and private sectors are allowed to provide MSWM services within the current legal framework. Besides, a clear and transparent bidding process for MSWM services delivery is open to all organisations that are able to deliver MSWM services. Yet, there is no evidence of any non-governmental representation in this sector; therefore, it does not actively participate within MSWM services planning and delivery. There is little acknowledgement of the role played by the informal sector regarding MSWM services delivery, as illustrated by a lack of effort on behalf of city institutions to include informal and private sector in the formal MSWM system. However, other cities such as Mina (Alsebaei 2014) and Guadalajara (Wilson et al. 2015) have improved the performance of their MSWM systems through the inclusion of these sectors. This inclusion has enhanced MSW recycling rates, allowed for extended collection coverage and minimised management costs (Babaei et al. 2015).

\subsubsection{Financial sustainability}

As MSWM is one of the most expensive services (Grazhdani 2016), MSWM bodies should have a reliable source of funds to deliver an efficient MSWM service. Respondents identified that the Ministry of Construction and Housing and Public Municipalities cover most of the capital costs required for MSWM in the city. Kerbala's local governorate also provides an extra fund to cover the cost of the management system during events. These institutions have rigorous accounting procedures in place for MSWM operational costs. However, as these accounts are not open to public scrutiny, there is no transparency or accountability. Most of the respondents believed that these institutions were able to provide more than $70 \%$ of the funds required for MSWM in the city during events but currently there is not enough capital to improve the present system. On top of this, there is no revenue generation plan; the system lacks user cost recovery such as MSW collection fees and disposal charges. Similar to the Hajj event (Alsebaei 2014), MSWM services during the Arba'een event are delivered free of charge. The city's MSWM institutions do not seem to mind spending large amounts of money on MSWM without any cost recovery.

\subsubsection{Management framework and institutional coherence}

The presence of updated MSWM legislation and regulations to accommodate any changes to the national situation plays a vital role in the success of MSWM system performance (Wilson et al. 2015). The Environmental Protection and Improvement Act number 27/2009 laid out principles for the protection of air, water and the environment in general. This act emphasises the importance of developing strategies for MSWM in an environmentally 
sound manner. However, the institutions were not able to formulate such a robust longterm strategy that adopts the hierarchy of MSWM. Seven participants thought that the current law was weak and outdated, focusing only on public cleaning and ignoring the development of the MSWM system. The law states that the Ministry of Construction and Housing and Public Municipalities is held responsible for the management of MSW at a national level while the Ministry of Environment is in charge of enforcing environmental legislations and monitoring the performance of MSWM systems. These ministries are also obliged to ensure that all activities operate without an adverse environmental footprint.

As a part of the Ministry of Construction and Housing and Public Municipalities, KM is responsible for the planning and delivery of MSWM services in the city including the collection, transportation and disposal of MSW. During events, since the organisational capacity of KM is not compatible with the amount of MSW produced, other institutions such as KMs, HAS and nearby city municipalities provide support in the form of MSW collection vehicles which collect and transport the MSW generated in the areas assigned to them by KM. Despite a well-organised and structured career progression, these bodies have a low percentage of suitably qualified and skilled key staff, poor staff training and limited development programmes. In parallel with national strategy, the city-wide MSWM plan is poor as it lacks an adequate strategy/plan; management institutions deliver MSWM services according to day-to-day operational planning. MSW data is not systematically collected/ recorded, because of the absence of a weighbridge at the landfill site and limited available finance. The absence of reliable data on MSW generation rates has led to open dumping and inadequate service delivery.

In common with other cities such as Mina (Alsebaei 2014), Qena (Wilson et al. 2013a), Managua and Nicaragua (Wilson et al. 2012), the national MSWM framework has not successfully introduced updated legislation to address current MSWM needs. This includes provision of an adequate MSWM strategy and effective implementation of the regulations and strategies necessary to improve the situation. There are several cities with comparable income levels that have achieved better performance, for example, Castries (Wilson et al. 2013b) and Guadalajara (Wilson et al. 2015). This implies that the MSWM institutions in Iraq can develop a more efficient MSWM framework to address identified challenges and improve current performance.

\subsection{Application of Wasteaware benchmark indicators on the Arba'een event MSWM system}

The Wasteaware benchmark indicators framework was developed by Wilson et al. (2015) to comprehensively evaluate MSWM systems in cities. This framework was applied to the city of Kerbala during large events to identify its strengths and the weaknesses and prioritise action for development. The framework evaluates the management system based on 8 composite qualitative indicators and 4 quantitative indicators. For each of the qualitative indicators, an assessment is made based on the collected data and authors' professional judgment, assigning a score $(0,5,10,15$ or 20$)$ against each criterion. For each indicator, the scores of the criteria are then summed and normalised to provide a percentage normalised score. For instance, the normalised score for an indicator that encompasses 6 criteria is the summation of the criteria scores divided by 120. A summary of indicators calculated for the MSWM system implemented during the Arba'een event is presented in Table 3.

The results of the Wasteaware benchmark indicators on the Arba'een MSWM system confirm that this system is weak. Despite all the focus and attention of Kerbala's MSWM 


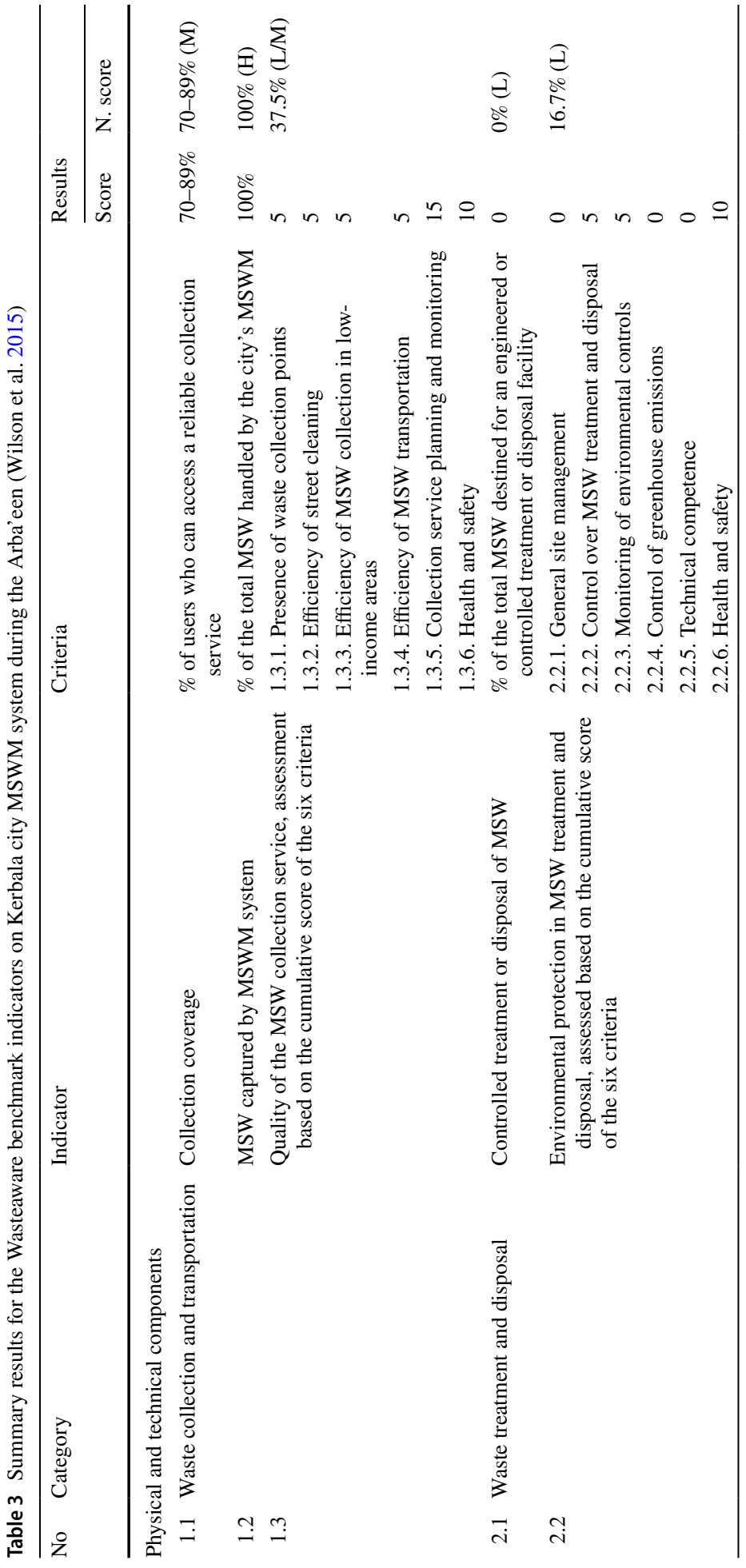




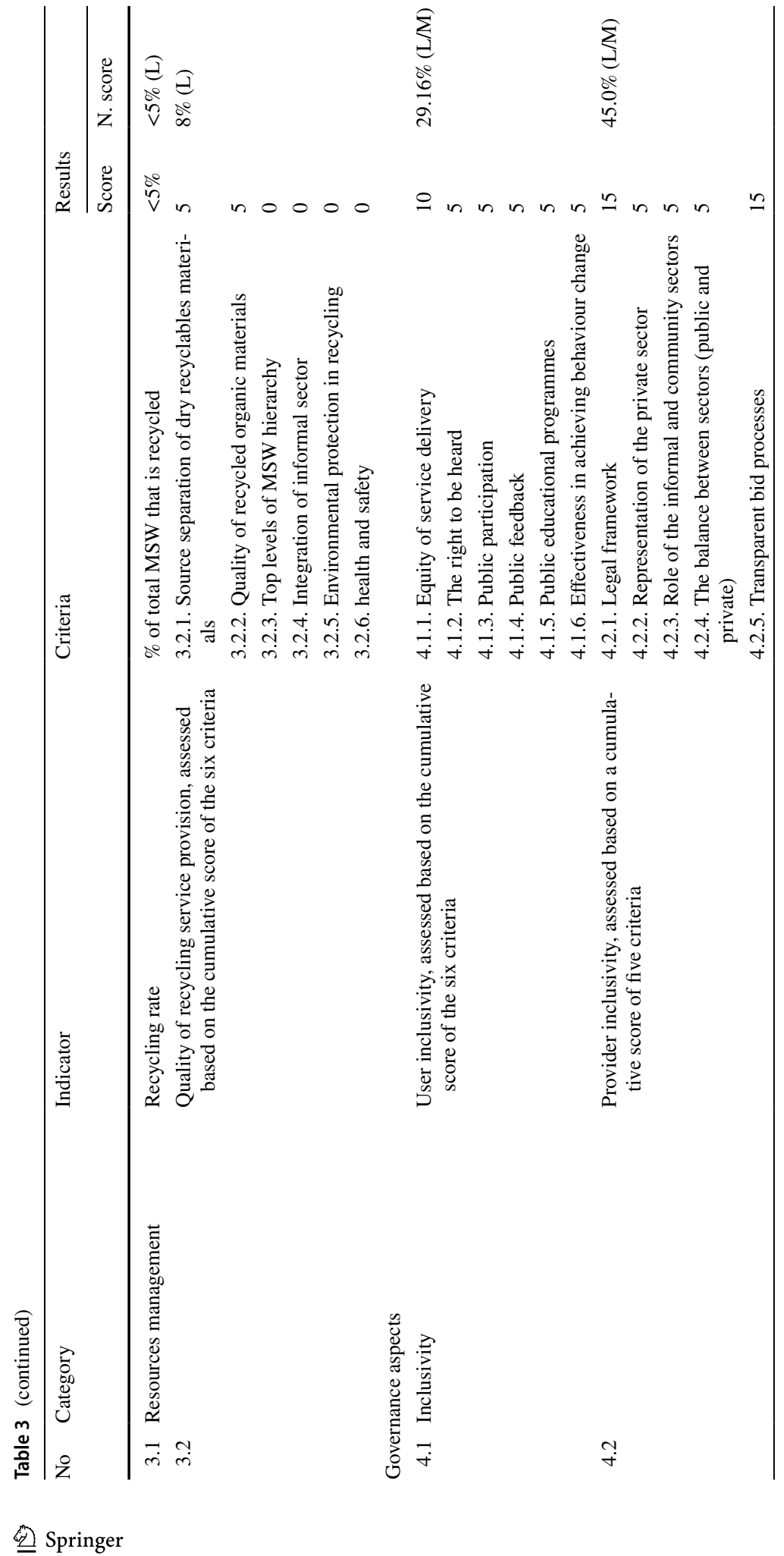




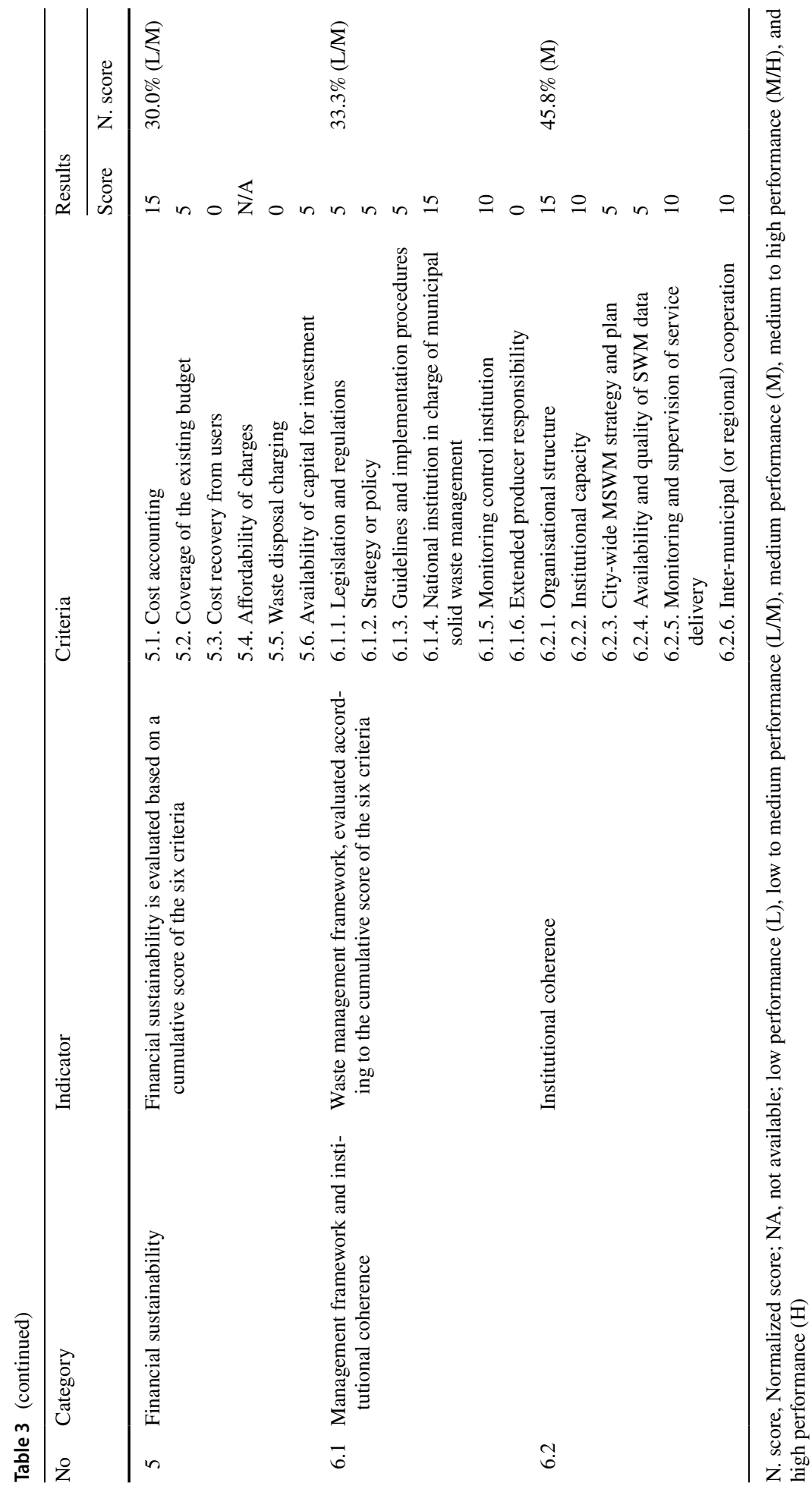


institutions on MSW collection and transportation, 100\% collection rates have yet not been achieved. A medium rating (41.6\%) was achieved for the quality of the collection service; this is almost identical to the quality of the collection service during Hajj in Mina (Alsebaei 2014). The existing landfill site in Kerbala is no more than a dumpsite, lacking for a weighbridge and appropriate general site management. Similar to Lahore (Masood et al. 2014), Qena (Wilson et al. 2013a) and Mina (Alsebaei 2014), methods of disposal are far from the requirements of a controlled landfill. Although a high fraction of the MSW produced during the Arba'een is recyclable, resource recovery still does not appear to be a major focus for the city authorities. Kerbala, like many middle-income cities (Wilson et al. 2013 b), still relies on informal recycling. A recycling rate of $\sim 5 \%$ was estimated by the management authorities; this is the same as Qena (Wilson et al. 2013b), a city with slightly better quality and environmental conditions (Wilson et al. 2013a).

Regarding governance aspects, MSWM system used during the Arba'een did not achieve good performance. To develop a sustainable MSWM system, inclusion of system users as well as all providers (private and informal) in planning and decision-making is essential (Wilson et al. 2015). The provider inclusivity indicators acquired a low to medium score because of the weak involvement of both private-sector companies and the informal sector. Public engagement is also limited due to the absence of a well-developed consultant mechanism. There is no permanent scheme of public education available through schools or colleges. The financial sustainability indicator also achieves a low to medium score of $30 \%$, as all the management costs are provided by the Iraqi government there being no cost recovery in the form of user fees. This is comparable to the financial suitability situation in Mina during the Hajj event, as Mina authorities also deliver an MSWM service free of charge. The overall assessment of the management framework and institutional coherence was similar to other developing cities such as Mina (Alsebaei 2014), Qena (Wilson et al. 2013a), Managua and Nicaragua (Wilson et al. 2012). The national MSWM framework has not successfully introduced updated legislation to address current and future MSWM needs, particularly during events.

\subsection{Recommendation for future priorities}

\subsubsection{Waste management authorities (KM, KMs and HSA)}

Several recommendations are made, aimed at the improvement of the current MSWM system in Kerbala, particularly during large events. It has been observed that most MSWM services are delivered by the public sector, with a negligible contribution by private and informal sectors. As most of the budget is focused on MSW collection and transportation, the inclusion of these sectors in MSW collection and transportation is expected to improve the collection service while minimising the collection cost. A similar system has already been active during the Hajj event in Mina (Alsebaei 2014). This would reduce the burden on the system and make it financially firm.

Kerbala's poor performance on MSW treatment and disposal indicators (indicators 2.1 and 2.2 in Table 3) calls for action towards improvement of its landfill site. In the short term, the current disposal site should be properly managed to comply with environmental regulations in Iraq. Proper site management could significantly reduce negative environmental impacts of the current site. In the long term, a new landfill site should be planned, a state-of-the-art site, with proper facilities for gas control and leachate management (Wilson 
et al. 2012). Several cities around the world have started attracting international investment to assist the development of such facilities including Kunming in China and Sousse in Tunisia (Wilson et al. 2012).

Formal recycling in Kerbala is absent, but noting the recycling rates by the informal sector has highlighted the contribution of the informal sector to MSWM in Kerbala. It was estimated by Kerbala's MSWM institutions that the current recycling rate is $\sim 5 \%$ of the MSW produced during the event; in the absence of informal recycling, the collected and disposed MSW would increase. Thus, proactive engagement with the informal sector is recommended, with the goal of developing a win-win solution. This solution could further increase recycling rates and cost savings for Kerbala, while improving the poor working conditions of the informal recyclers. There is a high percentage of organic MSW (57.9\%) in the MSW stream, and there is no composting facility in Kerbala. A new composting facility should be planned, as the city encompasses large agricultural lands (Khalaf and Hassan 2013), a strong market for the sale of compost. Utilising organic MSW as a compost could significantly minimise the amount of MSW disposed of in the landfill.

To engage the public as system users, enhancing their awareness regarding MSWM is crucial (Abdulredha et al. 2017a). The management institutions in Kerbala have not done enough to involve users in MSWM process. Involving the users in the design of MSWM services and providing information on the working of the system and the role of users are essential in the success of the proposed system. Utilising schools and educational institutions is a very effective method of disseminating this information.

In addition, the city is lacking target-based policies and proper planning. The current focus of MSWM institutions is on the improvement of collection and transportation services. Thus, this system will face serious problems if there is a reduction in the budget allocated for MSWM in the city, particularly during events. The system needs to be more reliant on its capacities. Applying affordable collection fees will have a positive impact on the financial sustainability of the MSWM system, while will, in turn, focus users' attention on the fact that they need to be responsible in terms of managing their MSW. The outdated and poor enforcement of existing laws and regulations are also reasons for the weak MSWM system in the city. Current policies and legislation need to be properly examined, updated and applied. The unavailability of reliable data regarding MSW generation rate and composition impacts on illegal dumping and the amount of MSW that could potentially be recovered. The development of an information system which can accurately capture such data could significantly enhance the planning and delivery of MSWM services.

\subsubsection{Religious events}

Religious events attract millions of pilgrims from different countries. Therefore, these events could be efficiently used to increase the public environmental awareness by using short, informative, and attractive teaching tools, such as posters and short movies. The religious authority responsible for managing the Arba'een event (HSA) could use events as a platform to raise the environmental awareness among pilgrims and even wider audience. The educational programme could be started by using some religious sermons during large events to disseminate this knowledge and educate pilgrims about the importance of their active participation in MSWM services. Additionally, religious 
events usually attract a big deal of media attention, where the bigger the event, the better the media coverage. Accordingly, efforts towards raising public environmental awareness could reach people who are interested but cannot attend such events.

\section{Conclusions}

This study provides a comprehensive investigation and assessment of the MSWM system applied in the city of Kerbala during AL-Arba'een, using the pre-developed Wasteaware benchmark indicators framework. This study can be used to address the lack of historical data on MSWM systems in developing countries, particularly during large religious events. It can also provide reliable information to assist decision-makers to prioritise actions for development, resulting in a reduction in the negative environmental footprint generated by MSWM services in Kerbala, Iraq.

The results revealed that Kerbala produces more MSW than other cities with comparable populations and income levels, due to the impact of religious events and the absence of proper MSWM activities. Events MSW account for more than $14 \%$ of the total MSW generated in the city each year. Its composition is comparable to that generated in other religious events, with a high percentage of organic and recyclable materials. The support from other municipalities during events is directed towards MSW collection and transportation, but the event area is still not adequately covered. Like many developing countries, the management facilities (transfer stations and landfill) are insufficient and very basic lacking in general site management and technical competencies. There is an urgent need to suitably manage the current facilities and to develop new fully engineered facilities.

Composting and recycling facilities are not in place. Significant investment in such facilities is required, giving a useful reduction in the weight of MSW that need to be disposed of and to make the system financially sustainable. The contribution of private and informal sectors should not be overlooked, as this can play a very important role in the improvement of the current MSWM system. As the public are also vital contributors to the success of the MSWM system, Kerbala's institutions need to make more effort to achieve proactive engagement with them. The current financial situation is weak which emphasise the importance of imposing user fees to improve the systems financial sustainability. Existing regulations and plans are very important weaknesses in the current system.

The approach used to develop the event's MSWM profile is generally the correct one to present an overall picture of MSWM during AL-Arba'een. The results showed that the city is lacking a proper MSWM strategy that focuses on an MSWM hierarchy. An effective and practical MSWM system is therefore required as this situation is likely to cause severe negative consequences to the environment and human health. Further research is needed to investigate the alternatives of introducing formal recycling scheme during religious events. Investigation of the public reaction towards a proposed recycling scheme is essential, as the practical participation of the public significantly improves the performance of that scheme.

Acknowledgements The present study is part of an ongoing investigation into the current municipal solid waste management system in Kerbala, specifically during religious events, conducted by Liverpool John Moores University. The authors are grateful to the Higher Committee for Education Development in Iraq for financial support. The authors are also thankful to the Kerbala Center for Studies and Research, Kerbala 
Municipality, Holy Shrines Authority and the University of Kerbala for their support during the data collection stage. The authors are thankful to the four anonymous referees for their insightful comments.

Open Access This article is distributed under the terms of the Creative Commons Attribution 4.0 International License (http://creativecommons.org/licenses/by/4.0/), which permits unrestricted use, distribution, and reproduction in any medium, provided you give appropriate credit to the original author(s) and the source, provide a link to the Creative Commons license, and indicate if changes were made.

\section{References}

Abdulredha, M., Al Khaddar, R., \& Jordan, D. (2017a). Hoteliers' attitude towards solid waste source separation through mega festivals: A pilot study in Karbala. In 3rd BUiD annual Doctoral research conference 2017, Dubai, 13 May 2017 (pp. 273-282). The British University in Dubai.

Abdulredha, M., Al Khaddar, R., Jordan, D., Alattabi, A., \& Alzeyadi, A. (2017b). Public participation in solid waste management during mega festivals: A pilot study. Paper presented at the 12th international conference for internet technology and secured transactions (ICITST-2017), University of Cambridge, UK, 11-14 December 2017.

Abdulredha, M., Al Khaddar, R. A. L., Jordan, D., \& Hashim, K. (2017c). The development of a waste management system in Kerbala during major pilgrimage events: Determination of solid waste composition. Procedia Engineering, 196, 779-784. https://doi.org/10.1016/j.proeng.2017.08.007.

Abdulredha, M., Al Khaddar, R., Jordan, D., Kot, P., Abdulridha, A., \& Hashim, K. (2018a). Estimating solid waste generation by hospitality industry during major festivals: A quantification model based on multiple regression. Waste Management, 77, 388-400. https://doi.org/10.1016/j.wasma n.2018.04.025.

Abdulredha, M., Al Khaddar, R., Kot, P., Jordan, D., \& Abdulridha, A. (2018b). Benchmarking of the current solid waste management system in Karbala, Iraq using Wasteaware benchmark indicators. Paper presented at the world environmental and water resources congress 2018, Minneapolis, Minnesota, 3-7 June 2018.

Abdulredha, M., Khaddar, R. A. L., Jordan, D., \& Alattabi, A. (2017d). Facing up to waste: How can hotel managers in Kerbala, Iraq, help the City Deal with its waste problem? Procedia Engineering, 196, 771-778. https://doi.org/10.1016/j.proeng.2017.08.006.

Ahmed, S. A., \& Ali, S. M. (2006). People as partners: Facilitating people's participation in public-private partnerships for solid waste management. Habitat International, 30(4), 781-796. https://doi. org/10.1016/j.habitatint.2005.09.004.

Al-Anbari, R., Alnakeeb, A., \& Abdulredha, M. (2014). Landfill site selection for Kerbala municipal solid wastes by using geographical information system techniques. Paper presented at the 1st international scientific conference on environment and sustainble development, University of Technology, Baghdad, Iraq, 29-30 December 2013.

Al-masoudi, R. M., \& Al-haidary, M. S. (2015). Spatial analysis of residential waste solid in the city of Karbala. Karbala University Journal, 13(2), 132-154.

Al-Modarresi, M. (2014). World's biggest pilgrimage now underway, and why you've never heard of it! https://www.huffingtonpost.co.uk/sayed-mahdi-almodarresi/arbaeen-pilgrimage_b_62037 56.html?utm_hp_ref=uk\&guccounter=1. Accessed March 10, 2018.

Alsebaei, A. F. (2014). Solid waste management and recycling during Hajj pilgrimage in Mina. Leeds: The University of Leeds.

Arbulu, I., Lozano, J., \& Rey-Maquieira, J. (2015). Tourism and solid waste generation in Europe: A panel data assessment of the Environmental Kuznets Curve. Waste Management, 46, 628-636. https://doi.org/10.1016/j.wasman.2015.04.014.

Arbulu, I., Lozano, J., \& Rey-Maquieira, J. (2016). The challenges of municipal solid waste management systems provided by public-private partnerships in mature tourist destinations: The case of Mallorca. Waste Management, 51, 252-258. https://doi.org/10.1016/j.wasman.2016.03.007.

Arbulú, I., Lozano, J., \& Rey-Maquieira, J. (2017). The challenges of tourism to waste-to-energy public-private partnerships. Renewable and Sustainable Energy Reviews, 72, 916-921. https://doi. org/10.1016/j.rser.2017.01.036.

Babaei, A. A., Alavi, N., Goudarzi, G., Teymouri, P., Ahmadi, K., \& Rafiee, M. (2015). Household recycling knowledge, attitudes and practices towards solid waste management. Resources, Conservation and Recycling, 102, 94-100. https://doi.org/10.1016/j.resconrec.2015.06.014. 
Barber, N. A., Kim, Y. H., \& Barth, S. (2014). The importance of recycling to U.S. festival visitors: A preliminary study. Journal of Hospitality Marketing \& Management, 23(6), 601-625. https://doi. org/10.1080/19368623.2014.844661.

Bryman, A. (2012). Social research methods (4th ed.). Oxford: Oxford University Press.

Bryman, A. (2015). Social research methods. Oxford: Oxford University Press.

Buzinde, C. N., Kalavar, J. M., Kohli, N., \& Manuel-Navarrete, D. (2014). Emic understandings of Kumbh Mela pilgrimage experiences. Annals of Tourism Research, 49, 1-18. https://doi. org/10.1016/j.annals.2014.08.001.

Caio, D., \& Fernando, F. (2013). Selective waste collection effectiveness indicators proposal applied in Ibipor Brazil as a waste management tool. In Proceedings of ISWA world congress, 2013 (pp. 7-11).

Cierjacks, A., Behr, F., \& Kowarik, I. (2012). Operational performance indicators for litter management at festivals in semi-natural landscapes. Ecological Indicators, 13(1), 328-337. https://doi. org/10.1016/j.ecolind.2011.06.033.

Cifrian, E., Galan, B., Andres, A., \& Viguri, J. R. (2012). Material flow indicators and carbon footprint for MSW management systems: Analysis and application at regional level, Cantabria, Spain. Resources, Conservation and Recycling, 68, 54-66. https://doi.org/10.1016/j.resco nrec.2012.08.007.

Collins, A., \& Cooper, C. (2016). Measuring and managing the environmental impact of festivals: The contribution of the Ecological Footprint. Journal of Sustainable Tourism, 25(1), 148-162. https:// doi.org/10.1080/09669582.2016.1189922.

Collins, A., Munday, M., \& Roberts, A. (2012). Environmental consequences of tourism consumption at major events. Journal of Travel Research, 51(5), 577-590. https://doi.org/10.1177/0047287511 434113

CSOI. (2015). Environmental statistics of Iraq for 2014. http://www.cosit.gov.iq/en/. Accessed June 28, 2016.

CSOI. (2016). Survey of hotels and tourist accommodations. http://www.cosit.gov.iq/en/. Accessed March 10, 2018.

El Hanandeh, A. (2013). Quantifying the carbon footprint of religious tourism: The case of Hajj. Journal of Cleaner Production, 52, 53-60. https://doi.org/10.1016/j.jclepro.2013.03.009.

Gangwar, K. K., \& Joshi, B. D. (2008). A preliminary study on solid waste generation at Har Ki Pauri, Haridwar, around the Ardh-Kumbh period of sacred bathing in the river Ganga in 2004. The Environmentalist, 28(3), 297-300. https://doi.org/10.1007/s10669-007-9147-z.

Getz, D., \& Page, S. J. (2016). Progress and prospects for event tourism research. Tourism Management, 52, 593-631. https://doi.org/10.1016/j.tourman.2015.03.007.

Giovanardi, M., Lucarelli, A., \& Decosta, P. L. E. (2014). Co-performing tourism places: The "Pink Night" festival. Annals of Tourism Research, 44, 102-115. https://doi.org/10.1016/j.annal s.2013.09.004.

Gómez, C. M., Lozano, J., \& Rey-Maquieira, J. (2008). Environmental policy and long-term welfare in a tourism economy. Spanish Economic Review, 10(1), 41-62. https://doi.org/10.1007/s1010 8-007-9028-0.

Grazhdani, D. (2016). Assessing the variables affecting on the rate of solid waste generation and recycling: An empirical analysis in Prespa Park. Waste Management, 48, 3-13. https://doi.org/10.1016/j. wasman.2015.09.028.

Greene, K. L., \& Tonjes, D. J. (2014). Quantitative assessments of municipal waste management systems: Using different indicators to compare and rank programs in New York State. Waste Management, 34(4), 825-836. https://doi.org/10.1016/j.wasman.2013.12.020.

Hashim, K. S., Al Khaddar, R., Jasim, N., Shaw, A., Phipps, D., Kot, P., et al. (2019). Electrocoagulation as a green technology for phosphate removal from river water. Separation and Purification Technology, 210, 135-144. https://doi.org/10.1016/j.seppur.2018.07.056.

Hotta, Y. (2014). 3R policy indicator factsheets-Discussion Paper. https://pub.iges.or.jp/system/files/ publication_documents/pub/discussionpaper/3890/3RIndicator_B5report_web.pdf. Accessed September 22, 2017.

Khalaf, R. M., \& Hassan, W. H. (2013). Evaluation of irrigation water quality index (IWQI) for AlDammam confined aquifer in the west and southwest of Karbala city. Iraq. International Journal of Civil Engineering (IJCE), 2(3), 21-34.

Lundmark, L., \& Stjernström, O. (2009). Environmental protection: An instrument for regional development? National ambitions versus local realities in the case of tourism. Scandinavian Journal of Hospitality and Tourism, 9(4), 387-405. https://doi.org/10.1080/15022250903273780. 
Martinho, G., Gomes, A., Ramos, M., Santos, P., Goncalves, G., Fonseca, M., et al. (2018). Solid waste prevention and management at green festivals: A case study of the Andancas Festival, Portugal. Waste Management, 71, 10-18. https://doi.org/10.1016/j.wasman.2017.10.020.

Masood, M., Barlow, C. Y., \& Wilson, D. C. (2014). An assessment of the current municipal solid waste management system in Lahore, Pakistan. Waste Management \& Research, 32(9), 834-847. https:// doi.org/10.1177/0734242X14545373.

Mateu-Sbert, J., Ricci-Cabello, I., Villalonga-Olives, E., \& Cabeza-Irigoyen, E. (2013). The impact of tourism on municipal solid waste generation: The case of Menorca Island (Spain). Waste Management, 33(12), 2589-2593. https://doi.org/10.1016/j.wasman.2013.08.007.

Matheson, C. M., Rimmer, R., \& Tinsley, R. (2014). Spiritual attitudes and visitor motivations at the Beltane Fire Festival, Edinburgh. Tourism Management, 44, 16-33. https://doi.org/10.1016/j.tourm an.2014.01.023

Menikpura, S. N., Gheewala, S. H., \& Bonnet, S. (2012). Framework for life cycle sustainability assessment of municipal solid waste management systems with an application to a case study in Thailand. Waste Management \& Research, 30(7), 708-719. https://doi.org/10.1177/0734242X12444896.

Mujtaba Husein, U. (2018). A phenomenological study of Arbaeen foot pilgrimage in Iraq. Tourism Management Perspectives, 26, 9-19. https://doi.org/10.1016/j.tmp.2017.11.015.

Panfiluk, E. (2015). Impact of a Tourist Event of a Regional Range on the Development of Tourism. Procedia: Social and Behavioral Sciences, 213, 1020-1027. https://doi.org/10.1016/j.sbspro.2015.11.520.

Peter, G. (2016). Planning for municipal solid waste management: The case of Greater Jos. Lagos: HeriotWatt University.

Rafiee, A., Gordi, E., Lu, W., Miyata, Y., Shabani, H., Mortezazadeh, S., et al. (2018). The impact of various festivals and events on recycling potential of municipal solid waste in Tehran, Iran. Journal of Cleaner Production, 183, 77-86. https://doi.org/10.1016/j.jclepro.2018.02.118.

Ryan, G. W., \& Bernard, H. R. (2003). Techniques to identify themes. Field Methods, 15(1), 85-109. https:// doi.org/10.1177/1525822x02239569.

Salt \& Light (2013). WYD Statistics from Rio's Local Organizing Committee. http://saltandlighttv.org/blogf eed/getpost.php?id=50099. Accessed May 18, 2018.

Scheinberg, A., Wilson, D. C., \& Rodic-Wiersma, L. (2010). Solid waste management in the world's cities. http://www.waste.nl/sites/waste.nl/files/product/files/swm_in_world_cities_2010.pdf. Accessed August 1, 2015.

Sheau-Ting, L., Sin-Yee, T., \& Weng-Wai, C. (2016). Preferred attributes of waste separation behaviour: An empirical study. Procedia Engineering, 145, 738-745. https://doi.org/10.1016/j.proeng.2016.04.094.

Thomas, J., \& Harden, A. (2008). Methods for the thematic synthesis of qualitative research in systematic reviews. BMC Medical Research Methodology, 8, 45. https://doi.org/10.1186/1471-2288-8-45.

UNEP. (2009). Independent environmental assessment: Beijing 2008 Olympic Games. https://www.unccl earn.org/sites/default/files/inventory/unep36.pdf. Accessed May 19, 2018.

UNWTO. (2018). 2017 international tourism results: The highest in seven years. http://media.unwto.org/ press-release/2018-01-15/2017-international-tourism-results-highest-seven-years. Accessed May 21, 2018.

Wilson, D. C. (2007). Development drivers for waste management. Waste Management and Research, 25(3), 198-207. https://doi.org/10.1177/0734242x07079149.

Wilson, D. C., Cowing, M. J., Mourdzhev, B., Gupta, S. K., Stretz, J., \& Schmidt, T. (2013b). Operator models. Respecting diversity: Annex 2-benchmark indicators. https://www.giz.de/en/downloads/giz20 13-swm-operator-models-sourcebook-en.pdf. Accessed May 18, 2016.

Wilson, D. C., Rodic, L., Cowing, M. J., Velis, C. A., Whiteman, A. D., Scheinberg, A., et al. (2015). 'Wasteaware' benchmark indicators for integrated sustainable waste management in cities. Waste Management, 35, 329-342. https://doi.org/10.1016/j.wasman.2014.10.006.

Wilson, D., Rodic, L., Cowing, M., Whiteman, A., Stretz, J., \& Scheinberg, A. (2013a) Benchmark indicators for integrated \& sustainable waste management (ISWM). In ISWA world congress 2013 Vienna, 7-9 October 2013.

Wilson, D. C., Rodic, L., Scheinberg, A., Velis, C. A., \& Alabaster, G. (2012). Comparative analysis of solid waste management in 20 cities. Waste Management and Research, 30(3), 237-254.

Wilts, H. (2012). National waste prevention programs: Indicators on progress and barriers. Waste Manag Res, 30(9 Suppl), 29-35. https://doi.org/10.1177/0734242X12453612.

Zaman, A. U. (2014). Identification of key assessment indicators of the zero waste management systems. Ecological Indicators, 36, 682-693. https://doi.org/10.1016/j.ecolind.2013.09.024.

Zeng, L., Zhu, H., Ma, Y., Huang, J., \& Li, G. (2014). Greenhouse gases emissions from solid waste: An analysis of Expo 2010 Shanghai, China. Journal of Material Cycles and Waste Management, 16(4), 616-622. https://doi.org/10.1007/s10163-014-0280-8. 
Zheng, P., Zhang, K., Zhang, S., Wang, R., \& Wang, H. (2016). The door-to-door recycling scheme of household solid wastes in urban areas: A case study from Nagoya, Japan. Journal of Cleaner Production. https://doi.org/10.1016/j.jclepro.2016.03.106.

\section{Affiliations}

Muhammad Abdulredha ${ }^{1,2}$ D $\cdot$ Patryk Kot $^{1} \cdot$ Rafid Al Khaddar $^{1} \cdot$ David Jordan $^{1} \cdot$ Ali Abdulridha ${ }^{3}$

4 Muhammad Abdulredha

m.a.abdulredha@2015.1jmu.ac.uk; m.alameri5@yahoo.com

1 Department of Civil Engineering, Liverpool John Moores University, Liverpool, UK

2 Department of Civil Engineering, Kerbala University, Kerbala, Iraq

3 Department of Civil Engineering, University of Warith AL-Anbiya'a, Kerbala, Iraq 